Verkaik, R., Antwerpen-Hogenraad, P. van, Veer, A. de, Francke, A., Huis in het Veld, J. Selfmanagement-support in dementia care: a mixed methods study among nursing staff. Dementia: International Journal of Social Research and Practice: 2017, 16(8), 1032-1044

\begin{tabular}{l|l} 
Postprint & 1.0
\end{tabular}

Version

Journal website http://dem.sagepub.com/content/early/2016/02/22/1471301216632416.long

Pubmed link http://www.ncbi.nlm.nih.gov/pubmed/26908547

DOI $\quad 10.1177 / 1471301216632416$

This is a NIVEL certified Post Print, more info at http://www.nivel.eu

\title{
Self-management-support in dementia care: A mixed methods study among nursing staff
}

\author{
RENATE VERKAIK ${ }^{1}$, PAULIEN VAN ANTWERPEN-HoOgENRAAD ${ }^{2}$, ANKE DE VEER ${ }^{3}$, ANNEKE \\ FRANCKE ${ }^{4}$, JUDITH HUIS IN HET VELD ${ }^{5}$ \\ ${ }^{1}$ Netherlands Institute for Health Services Research, Utrecht, the Netherlands \\ ${ }^{2}$ Buurtzorg Nederland, Delft, the Netherlands \\ ${ }^{3}$ Netherlands Institute for Health Services Research, Utrecht, the Netherlands \\ ${ }^{4}$ Netherlands Institute for Health Services Research, Utrecht, the Netherlands; \\ VUmc/EMGOp Institute, Amsterdam, the Netherlands \\ ${ }^{5} \mathrm{VUmc/EMGOp}$ Institute, Amsterdam, the Netherlands
}

\begin{abstract}
Background: Self-management in patients and family caregivers confronted with dementia is not self-evident. Self-management skills may be limited because of the progressive cognitive decline of the patient and because family caregivers are often also very aged. Self-management support by nursing staff is therefore of paramount importance.

Objectives: To gain insight into how nursing staff perceive their selfmanagement support tasks, and how they put them into practice. Research questions are: 'What are the opinions and experiences of Dutch nursing staff working in home care or residential elderly care regarding self-management support for people with dementia and their family caregivers?' and 'Do nursing staff feel sufficiently trained and skilled for self-management support?'.

Methods: A mixed methods approach was used, combining cross-sectional quantitative survey data from 206 Dutch nursing professionals with qualitative interviews among 12 nursing staff working in home care or residential elderly care in The Netherlands.

Results: Nursing staff working in home care experienced self-management support of people with dementia as a part of their job and as an attractive task. They consider 'helping people with

dementia to maintain control over their lives by involving them in decisions in daily care' the essence of self-management support. Nursing staff saw family caregivers as their main partners in providing self-management support to the patient. They were less aware that family caregivers themselves might also need self-management support. Nursing staff often felt insufficiently trained to give
\end{abstract}


Verkaik, R., Antwerpen-Hogenraad, P. van, Veer, A. de, Francke, A., Huis in het Veld, J. Selfmanagement-support in dementia care: a mixed methods study among nursing staff. Dementia: International Journal of Social Research and Practice: 2017, 16(8), 1032-1044

adequate self-management support. RN's and CNA's did not differ in their opinions, experiences and training needs.

Conclusions: Nursing staff in home care do consider self-management support an important and attractive task in dementia care. Their skills for providing selfmanagement support to patients with dementia and family caregivers need improvement.

Recommendations: Nursing staff need sufficient training to enable the proper provision of self- management support for people with dementia. More attention should also be given to the support of self-management for family caregivers.

\section{INTRODUCTION}

Most people with progressive diseases like dementia prefer to have control over their own lives and health care for as long as possible. Keeping in control means, among other things, that patients perform self-management activities. In line with the wellknown definition of Barlow, Wright, Sheasby, Turner, and Hainsworth (2002), we define self-management as "the individual's ability to manage the symptoms, treatment, physical and psychosocial consequences and lifestyle changes inherent in living with a chronic condition'. Supporting people in decisions and actions that promote self-management is called self- management support, requiring a 'cooperative relationship' between the patient, the family and the professionals. A review by the Health Foundation shows that supporting self-management can have benefits for people's attitudes and behaviours, quality of life, clinical symptoms and use of healthcare resources (de Silva, 2011). By giving self- management support, nurses and other healthcare professionals can help patients and their families to manage their condition and develop the confidence to make choices about the care they need.

Although there is a growing awareness in health care that self-management and selfmanagement support are important (Franek, 2013), the actual practice of selfmanagement activities is not self-evident in all patient groups. For instance, selfmanagement in people with dementia is hampered by their progressive cognitive decline. Nonetheless, people with dementia have to manage many problems related to their dementia every day: not just the 'forgetting', but often also behavioural and psychological problems like depression, apathy and agitation (Saz et al., 2009; Verkaik, Francke, van Meijel, Ribbe,

$\&$ Bensing, 2009). Dementia often leads to much reliance by the patient on family care, which may cause stress, anxiety and depressed moods in family caregivers (e.g. Cerejeira, Lagarto, \& Mukaetova-Ladinska, 2012). Therefore, it is important that family caregivers also have support from professionals, both in managing the patient's challenges and their own. Hence self-management support in people with dementia is about supporting the person with dementia and their family caregivers individually and together, in fulfilling their individual and shared needs. Selfmanagement refers to how the systems of people with dementia and their family caregivers manage the symptoms, problems, treatment and other challenges related to the dementia in their daily life.

Nursing staff are particularly appropriate professionals for providing selfmanagement support because a core competency of nursing staff is to empower patients and to enable people to understand and cope with their disease, its treatment 
Verkaik, R., Antwerpen-Hogenraad, P. van, Veer, A. de, Francke, A., Huis in het Veld, J. Selfmanagement-support in dementia care: a mixed methods study among nursing staff. Dementia: International Journal of Social Research and Practice: 2017, 16(8), 1032-1044

and its consequences (Royal College of Nursing (RCN), 2003). However, little research has been done on how nursing staff perceive their self-management support tasks, and how they perform these tasks in daily dementia care (Mountain, 2006). This paper aims to provide insight into how nursing staff working in those settings where dementia care is mostly delivered - home care and residential elderly care perceive their self-management support tasks. Therefore, we address the following research questions:

- What are the opinions and experiences of nursing staff working in home care or residential elderly care regarding self-management support for people with dementia and their family caregivers?

- Do nursing staff feel sufficiently trained and skilled for self-management support?

\section{METHODS}

\section{Study design}

We used a mixed methods design, combining secondary analyses of cross-sectional quantitative survey data with qualitative semi-structured interviews.

\section{Participants}

\section{Survey participants.}

The study started with the secondary analysis of an existing quantitative dataset. This dataset came from a cross-sectional survey among a national representative sample of nursing staff known as the Nursing Staff Panel (de Veer, Fleuren, Bekkema, \& Francke, 2011). The data were collected in 2012. The data that were analysed came from 206 nursing staff members, namely 46 Registered Nurses (RNs) and 160 Certified Nurse Assistants (CNAs). Only those data were eligible for analysis that were provided by nursing staff meeting the following criteria: 1. being an $\mathrm{RN}$ or CNA, 2. working in residential elderly care or home care, 3. caring for people with dementia (people with dementia were one of client groups that they worked with most). The characteristics of the 206 nursing staff whose data were used are presented in Table 1. As this table shows, nursing staff working in home care, staff working in assisted living facilities and staff working in nursing homes were all included. Assisted living facilities and nursing homes both fall in the category of 'residential elderly care'. The difference is that, in the Netherlands, more complex nursing and medical care is delivered in nursing homes than in assisted living facilities (Schols, Crebolder, \& van Weel, 2004).

\section{Semi-structured interview participants.}

We then performed qualitative interviews in order to deepen, refine and illustrate the insights gained from the quantitative analysis. The interviews were held with 12 nursing staff working in home care or in residential elderly care. Regarding residential elderly care, we only recruited participants working in nursing homes. The decision not to recruit professionals from assisted living facilities was made because at the time of the interviews (January-February 2014) Dutch residential elderly care underwent a major transition. One of the consequences was that many assisted living facilities had to close or convert to a nursing-home function. 
Verkaik, R., Antwerpen-Hogenraad, P. van, Veer, A. de, Francke, A., Huis in het Veld, J. Selfmanagement-support in dementia care: a mixed methods study among nursing staff. Dementia: International Journal of Social Research and Practice: 2017, 16(8), 1032-1044

Participants for the interviews were recruited from within the research team's nivel professional networks. Purposive sampling was conducted, aimed at having a range of different educational levels, ages, settings and geographical areas. Twelve participants were recruited and interviewed in total. Twelve interviews appeared to be sufficient to reach data saturation, which is consistent with a review by Guest, Bunch, and Johnson (2006) indicating that 12 interviews are often sufficient to reach saturation in a relatively homogenous group. The characteristics of the 12 nursing staff who were interviewed are presented in Table 2.

\section{[TABLE 1]}

\section{Data collection}

\section{Survey data collection.}

Secondary analyses were performed on an existent dataset from the Nursing Staff Panel. The survey questionnaire data were all collected in January-February 2012. The survey questionnaire had been tested for comprehensibility, clarity and content validity. It included items on nursing staff's experiences, opinions and perceived expertise regarding self-management support. Questions about self-management support were based on a large survey about the self-management support needs of chronically ill patients, described in van Houtum, Rijken, Heijmans, and Groenewegen (2013).

\section{Data collection for the semi-structured interviews.}

The 12 interviews were conducted from March to May 2014 by the second author $(\mathrm{PH})$, in all cases with a co-reviewer (a nursing science student or a $\mathrm{PhD}$ researcher). All interviews took place at the respondent's home or work address and lasted between half an hour and an hour. A semi-structured topic guide was used to ensure that all relevant topics came up for discussion. The content of the topic guide was based on insights from the analyses in the quantitative part of the study. The topics were: (1) what participants found essential in self-management support in dementia care; (2) whether they found self-management support an attractive task; (3) their actual practice and experiences with self-management support for dementia patients; (4) self-management support in relation to the family caregivers of people with dementia; (5) the skills and knowledge needed for self-management support in dementia care.

\section{[TABLE 2]}

\section{Data analysis}

\section{Survey data analysis.}

Descriptive statistics (frequencies and percentages) and chi-squared tests were used to analyse the existent set of survey data. Analyses were performed using SPSS 19.

\section{Data analysis for the semi-structured interviews.}

The audio recordings of the interviews were transcribed verbatim and anonymised. Three authors (PJH, RV and JHV) were involved in the entire process of data analysis. They read the transcripts individually, and after every third interview they 
Verkaik, R., Antwerpen-Hogenraad, P. van, Veer, A. de, Francke, A., Huis in het Veld, J. Selfmanagement-support in dementia care: a mixed methods study among nursing staff. Dementia: International Journal of Social Research and Practice: 2017, 16(8), 1032-1044

discussed the interim analyses together. The principles of the Qualitative Analysis Guide of Leuven, which are largely based on grounded theory methodology, were used as a guide for the steps in the qualitative data analysis (Dierckx de Casterle', Gastmans, Bryon, \& Denier, 2012). The coding process started with open and axial coding to identify, code and categorise the main themes in the transcripts. Theme's mainly followed the topics of the interview guide. Next selective coding was done to find connections between the categories (Boeije, 2010). The software programme MAXQDA, version 11.0.8, was used as an aid in the coding and analysis process. The use of this programme, the adherence to the principles of constant comparison (Glaser \& Straus, 1967, p. 105), and the discussions of the interim and final analyses within the research team all helped enhance the quality of the analysis.

\section{Ethical considerations}

As this was a questionnaire and interview based study of nursing staff with no patient involvement, approval from an ethics committee is not required under Dutch law. Study participation was voluntary. Participants to the interviews were informed about the study with an information letter and signed an informed consent form before the interview took place. Data were anonymised before analyses and storage.

\section{RESULTS}

\section{Opinions about and experiences with self-management support}

The survey data showed that a large majority $(83.2 \%)$ of the responding nursing staff considered self-management support a part of their job. Those who worked in home care were more likely to think this $(93.2 \%)$ than those working in assisted living facilities $(81.1 \%)$ or in nursing homes $(62 \%)$. No differences between RN's and CNA's were found. Self- management support activities that were frequently mentioned were self-management support in personal care and in dealing with an uncertain future. Activities that were mentioned less often were, e.g. supporting the patient in using new technologies (e.g. e-health programmes) that promote self-management (see Table 3).

In addition, the majority $(61.6 \%)$ thought that it would be appealing to spend more time on self-management support in the future (not in table). However, there were significant differences between healthcare settings in this regard ( $\mathrm{p} 1 / 40.001)$. Those who worked in home care were more likely to hold this opinion $(75.7 \%)$ than nursing staff working in residential elderly care: only $38.8 \%$ in nursing homes and $62.7 \%$ in assisted living facilities found it an attractive idea to spend more time on selfmanagement support in the future. RN's and CNA's did not differ in their opinions. The qualitative interviews also show that nursing staff see self-management support as part of their work. In the interviews, participants were asked what they saw as the essence of self-management support in dementia care. Although some said that selfmanagement support was not a word they often used, most said that they associated it with helping a person with dementia to maintain control over his/her life.

"That the client feels that he is still in control of his life and that he can make his own decisions [...]. That they still have the feeling that they can make their own choices in their lives. I think that is very important' (Participant no. 10, who works in a nursing home). In addition, participants mentioned that self-management support will become more important in the future because more patients will remain at home 
Verkaik, R., Antwerpen-Hogenraad, P. van, Veer, A. de, Francke, A., Huis in het Veld, J. Selfmanagement-support in dementia care: a mixed methods study among nursing staff. Dementia: International Journal of Social Research and Practice: 2017, 16(8), 1032-1044

as long as possible and future patients will probably be even more willing to have control over their own lives.

"The generation of people aged around 70 are getting more emancipated and are willing to look things up by themselves, for example by attending a discussion group or searching on the Internet for information about the development of a disease in an early stage. I think that our current clients don't do that because they haven't grown up with it' (Participant no. 5, who works in home care).

\section{[TABLE 3]}

Most examples concerned self-management support in personal care (e.g. bathing, eating and getting dressed). The participants promoted self-management by encouraging the person with dementia to perform these activities themselves. They described their position as a 'guide' in this process.

Participants also said that they tried to involve family caregivers in the process of self- management support.

"It is good to have conversations with the family caregivers and to explain and check if they know what the process of dementia means. It is also important to explain the goals of your nursing interventions"'. (Participant no. 6, who works in home care).

Some participants said that they enhanced family involvement in the selfmanagement support of the patient through planned and spontaneous conversations with the family. Some also said that they supported the family caregivers in dealing with the disease and its consequences by giving them information and by referring them to other facilities, such as Alzheimer Cafe's s (meeting points for clients and family caregivers confronted with dementia) or a dementia case manager. However, some other participants mentioned that family caregivers were not yet getting sufficient support in the self-management of their own problems. They suggested that nursing staff are not always aware that family caregivers need support in managing their own problems as well (e.g. caregiver stress).

The interviews also show that, in general, participants experienced self-management support as an attractive part of their job, and they sometimes saw positive effects in their clients.

"If you allow clients to be in control of their own lives and [..] if you respect them, there will be less reason for aggression" (Participant no. 8, who works in a nursing home).

Most participants described continuity in care (few changes in personnel), good contact with the family caregivers and the client's cooperation as facilitators of selfmanagement support. Some participants also said that it helps if self-management support is defined in the policy of their care organisation.

Perceived barriers preventing the provision of self-management support were lack of time, and particularly in nursing homes, staff shortages and an advanced stage of dementia. Some participants also said that it is difficult to give a person with dementia an active role, particularly those in the advanced stages of dementia in nursing homes, because the staff are used to taking over care tasks rather than supporting patients in self-management. In addition, participants stated that not all persons with dementia want to participate in self- management activities because some believe it is the professionals' task to care for them rather than have them doing things themselves. 
Verkaik, R., Antwerpen-Hogenraad, P. van, Veer, A. de, Francke, A., Huis in het Veld, J. Selfmanagement-support in dementia care: a mixed methods study among nursing staff. Dementia: International Journal of Social Research and Practice: 2017, 16(8), 1032-1044

\section{Knowledge, skills and training needs regarding self-management support.}

The secondary analysis of the survey data showed that $66.5 \%$ of the participants thought they had sufficient knowledge and skills to deliver self-management support (see Table 4). The other participants however thought that their knowledge and/or skills were inadequate for providing self-management support for chronically ill clients. Again, no differences between RN's and CNA's were found.

In the interviews, almost all participants pointed to training needs, especially in supporting self-management in people with advanced dementia in nursing homes.

"I am really curious about what you can do (concerning self-management) in people with advanced dementia. Because that seems difficult. ... in my opinion they do not have a good overview of (situations)... . helping themselves in small tasks does seem possible however'. (Participant no. 1, who works in a nursing home)

Nursing staff preferred to have training in the form of case discussions in team meetings where they can learn from one another and talk about 'real-life' cases.

"I would like to have training. In my own team... So that you have statements or case descriptions, and discuss these... So that you could learn from one another. (Participant no. 3, who works in home care)

Some participants also stated that they did not need additional training because they could consult professionals in other disciplines, such as a dementia case manager working in home care, whenever they had difficulties providing self-management support.

\section{DISCUSSION}

\section{Main findings}

Dutch nursing staff saw self-management support as part of their job. They defined self- management support as helping clients to maintain control over their lives by involving them in decisions in daily care.

Both in home care and in nursing homes, nursing staff saw family caregivers as partners in providing self-management support to the patient. This is an important result since involving both family caregivers and the person with dementia in selfmanagement interventions contributes to its effectiveness (Parker, Mills, \& Abbey, 2008). Nursing staff were however less often aware that family caregivers themselves may also have a need for support in self- managing their own problems (e.g. caregiver stress).

The majority of staff working in home care thought that spending more time on selfmanagement support in the future was an appealing idea, but fewer participants working in residential elderly care found this an attractive task. These results may be explained by the fact that clients in residential care, particularly those in a nursing home, are more likely to have advanced dementia than clients who live at home, and nursing staff see fewer opportunities for self-management support in advanced dementia.

Despite the importance they attached to self-management support as part of their work, nursing staff often said that they had limited skills and knowledge about self- 
Verkaik, R., Antwerpen-Hogenraad, P. van, Veer, A. de, Francke, A., Huis in het Veld, J. Selfmanagement-support in dementia care: a mixed methods study among nursing staff. Dementia: International Journal of Social Research and Practice: 2017, 16(8), 1032-1044

management support for dementia patients and family caregivers. According to nursing staff, facilitators of self-management support for people with dementia and family caregivers are continuity in care personnel, good contacts with the family caregivers, cooperation from the client and attention to the issue of self-management support in the policy of the care organisation involved. In contrast, limited time, staff shortages and an advanced stage of dementia in the client were mentioned as barriers impeding self-management support. These barriers particularly play a role in nursing homes.

Interestingly, no differences were found between RN's and CNA's regarding their opinions and experiences with self-management in dementia and their perceived skills and training needs. This might be related to the fact that for both professions self-management support in dementia is a relatively new task.

This is one of the few studies on self-management or self-management support in dementia and, to our knowledge, the first study specifically focussing on the opinions and experiences of nursing staff. Insight into the opinions and experiences of nursing staff is important because nursing staff are the key professionals in the provision of self- management support. Studies by Martin, Turner, Wallace, Choudhry, and Bradbury (2013) and Toms, Quinn, Anderson, \& Clare (2015) confirm the importance of a whole- systems approach to self-management support for people with dementia, systems in which nursing staff are important players. Results of the current study show that a whole-systems approach to self-management support in dementia is only partly recognized by nursing staff. Nursing staff see family caregivers as their main partners in providing self-management support to people with dementia. They are however less aware that family caregivers themselves might also need self-management support.

Another question is what type of self-management support interventions nursing staff should apply to support self-management in people with dementia and their family caregivers. In a recently published meta-review we show that evidence exists for the effectiveness of self-management support interventions targeting the psychological wellbeing of family caregivers and for support interventions targeting the provision of information to family caregivers (Huis in het Veld, Verkaik, Mistian, Van Meijel, \& Francke, 2015). For people with early dementia, a recent review by Quinn, Toms, Anderson, and Clare (2015) shows that self-management components have already been incorporated into group-based interventions. Further studies are needed to determine the effectiveness of self-management (support) interventions with this population.

\section{Strengths and limitations.}

The validity of the results was enhanced by combining survey data and semistructured interviews (method triangulation) (Polit \& Beck, 2012). Consequently we were able to present a realistic picture of how nursing staff perceive self-management support.

A limitation is that the dataset with survey data that we used for secondary analyses did not explicitly focus on self-management support in dementia care. Although we only analysed data from participants who had indicated that people with dementia constituted one of their main patient groups, they may have considered other chronically ill patients as well when answering the survey questions. This limitation was however compensated by the fact that in the qualitative interviews we focussed 
Verkaik, R., Antwerpen-Hogenraad, P. van, Veer, A. de, Francke, A., Huis in het Veld, J. Selfmanagement-support in dementia care: a mixed methods study among nursing staff. Dementia: International Journal of Social Research and Practice: 2017, 16(8), 1032-1044

very specifically on self-management support for people with dementia and their families. The data from the interviews confirmed and deepened the results from the survey data.

\section{CONCLUSIONS}

The opinions and experiences of nursing staff regarding self-management support in dementia care are generally positive. Nursing staff in home care see more possibilities for self-management support in dementia care than nursing staff in residential elderly care. RN's and CNA's do not differ in their opinions and experiences. Sufficient time and training are needed to enable staff to deliver selfmanagement support properly to patients with dementia and their family caregivers. More attention should also be given to self-management support by nursing staff for family caregivers.

\section{Declaration of conflicting interests}

The author(s) declared no potential conflicts of interest with respect to the research, authorship, and/or publication of this article.

\section{Funding}

The author(s) disclosed receipt of the following financial support for the research, authorship, and/or publication of this article: this study forms part of the research programme 'NurseSMS-Nurses Self- management Support for people facing progressive incurable diseases' (2014-2019, file number 80- 80705-98-027), which is funded by the Dutch ZonMw-programme 'TussenWetenenDoen'.

\section{REFERENCES}

Barlow, J., Wright, C., Sheasby, J., Turner, A., \& Hainsworth, J. (2002). Self-management approaches for people with chronic conditions: A review. Patient Education and Counseling, 48(2), 177-187.

Boeije, H. (Ed.). (2010). Analysis in qualitative research. London: Sage publications.

Cerejeira, J., Lagarto, L., \& Mukaetova-Ladinska, E. B. (2012). Behavioral and psychological symptoms of dementia. Frontiers in Neurology, 3(73), 1-21. DOI: 10.3389/fneur.2012.00073.

de Silva, D. (2011). Evidence: Helping people help themselves. A review of the evidence considering whether it is worthwhile to support self-management. London: Health Foundation.

de Veer, A. J., Fleuren, M. A., Bekkema, N., \& Francke, A. L. (2011). Successful implementation of new technologies in nursing care: A questionnaire survey of nurseusers. BMC Medical Informatics and Decision Making, 11, 67.

Dierckx de Casterle' , B., Gastmans, C., Bryon, E., \& Denier, Y. (2012). Quagol: A guide for qualitative data analysis. International Journal of Nursing Studies, 49(3), 360-371.

Franek, J. (2013). Self-management support interventions for persons with chronic disease: An evidence-based analysis. Ontario Health Technology Assessment Series, 13(9), 1-60.

Glaser, B. G., \& Strauss, A. L. (1967). The discovery of grounded theory: Strategies for qualitative research. Hawthorne, NY: Aldine.

Guest, G., Bunch, A., \& Johnson, L. (2006). How many interviews are enough? An experiment with data saturation and variability. Field Methods, 18(1), 59-82.

Huis in het Veld, J., Verkaik, R., Mistian, P., Van Meijel, B., \& Francke, A. L. (2015). The effectiveness of interventions in supporting self-management of informal caregivers of people with dementia: A systematic meta review. BMC Geriatrics, 15, 147. 
Verkaik, R., Antwerpen-Hogenraad, P. van, Veer, A. de, Francke, A., Huis in het Veld, J. Selfmanagement-support in dementia care: a mixed methods study among nursing staff. Dementia:

International Journal of Social Research and Practice: 2017, 16(8), 1032-1044

Martin, F., Turner, A., Wallace, L. M., Choudhry, K., \& Bradbury, N. (2013). Perceived barriers to self-management for people with dementia in the early stages. Dementia (London), 12(4), 481-493.

Mountain, G. A. (2006). Self-management for people with early dementia: An exploration of concepts and supporting evidence. Dementia, 5, 429-446.

Parker, D., Mills, S., \& Abbey, J. (2008). Effectiveness of interventions that assist caregivers to support people with dementia living in the community: A systematic review. International Journal of Evidence Based Healthcare, 6, 137-172.

Polit, D. F., \& Beck, C. T. (Eds.). (2012). Nursing research: Generating and assessing evidence for nursing practice (9th ed.). China: Wolters Kluwer Health.

Quinn, C., Toms, G., Anderson, D., \& Clare, L. (2015). A review of self-management interventions for people with dementia and mild cognitive impairment. Journal of Applied Gerontology. Epub ahead of print 21 January. pii: 0733464814566852.

Royal College of Nursing (RCN). (2003). Defining nursing. London: RCN.

Saz, P., Lo' pez-Anto' n, R., Dewey, M. E., Ventura, T., Martı' n, A., Marcos, G., ... Lobo, A. (2009). Prevalence and implications of psychopathological non-cognitive symptoms in dementia. Acta Psychiatrica Scandinavica, 119(2), 107-116.

Schols, J. M., Crebolder, H. F., \& van Weel, C. (2004). Nursing home and nursing home physician: The Dutch experience. Journal of the American Medical Directors Association, 5(3), 207-212.

Toms, G. R., Quinn, C., Anderson, D. E., \& Clare, L. (2015). Help yourself: perspectives on self- management from people with dementia and their caregivers. Qualitative Health Research, 25(1), 87-98.

van Houtum, L., Rijken, M., Heijmans, M., \& Groenewegen, P. (2013). Self-management support needs of patients with chronic illness: Do needs for support differ according to the course of illness? Patient Education and Counseling, 93(3), 626-632.

Verkaik, R., Francke, A. L., van Meijel, B., Ribbe, M. W., \& Bensing, J. M. (2009). Comorbid depression in dementia on psychogeriatric nursing home wards: Which symptoms are prominent? American Journal of Geriatric Psychiatry, 17(7), 565-573.

\section{TABLES}

Table I. Characteristics of the respondents in the secondary analyses of survey data $(n=206)$.

\begin{tabular}{lc}
\hline Charecteristics & $\%$ \\
\hline Gender: Female & 96.1 \\
Age & \\
$\quad<35$ & 10.7 \\
$36-45$ & 21.8 \\
$46-55$ & 37.4 \\
$56-65$ & 30.1 \\
Healthcare sector: & 26.7 \\
$\quad$ Residential elderly care: nursing home & 35.0 \\
Residential elderly care: home for the elderly & 38.3 \\
$\quad$ Home care & \\
Educational level & 8.3 \\
RN, bachelor level & 14.1 \\
RN, associate level & 77.7 \\
CNA, associate level & \\
\hline
\end{tabular}


Verkaik, R., Antwerpen-Hogenraad, P. van, Veer, A. de, Francke, A., Huis in het Veld, J. Selfmanagement-support in dementia care: a mixed methods study among nursing staff. Dementia: International Journal of Social Research and Practice: 2017, 16(8), 1032-1044

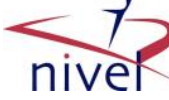

Table 2. Demographic characteristics of the interviewees $(N=12)$.

\begin{tabular}{|c|c|c|c|c|c|}
\hline Participant & Gender & Age & Professional level & Healthcare sector & Area \\
\hline I & Female & $<30$ & $\begin{array}{l}\text { RN with a bachelor } \\
\text { degree }\end{array}$ & $\begin{array}{l}\text { Residential } \\
\text { elderly care }\end{array}$ & $\begin{array}{l}\text { City, western part of the } \\
\text { Netherlands }\end{array}$ \\
\hline 2 & Female & $40-50$ & CNA & $\begin{array}{l}\text { Residential } \\
\text { elderly care }\end{array}$ & $\begin{array}{l}\text { City, southern part of the } \\
\text { Netherlands }\end{array}$ \\
\hline 3 & Female & $30-40$ & CNA & Home care & $\begin{array}{l}\text { Rural area, central part of } \\
\text { the Netherlands }\end{array}$ \\
\hline 4 & Male & $<30$ & CNA & Home care & $\begin{array}{l}\text { City, western part of the } \\
\text { Netherlands }\end{array}$ \\
\hline 5 & Female & $40-50$ & $\begin{array}{l}\text { RN with associate } \\
\text { level degree }\end{array}$ & Home care & $\begin{array}{l}\text { Rural area, western part } \\
\text { of the Netherlands }\end{array}$ \\
\hline 6 & Female & $<30$ & $\begin{array}{l}\mathrm{RN} \text { with bachelor } \\
\text { degree }\end{array}$ & $\begin{array}{l}\text { Residential } \\
\text { elderly care }\end{array}$ & $\begin{array}{l}\text { City, southern part of the } \\
\text { Netherlands }\end{array}$ \\
\hline 7 & Female & $50-60$ & CNA & $\begin{array}{l}\text { Residential } \\
\text { elderly care }\end{array}$ & $\begin{array}{l}\text { City, central part of the } \\
\text { Netherlands }\end{array}$ \\
\hline 8 & Female & $<30$ & $\begin{array}{l}\text { RN with associate } \\
\text { level degree }\end{array}$ & $\begin{array}{l}\text { Residential } \\
\text { elderly care }\end{array}$ & $\begin{array}{l}\text { City, northern part of the } \\
\text { Netherlands }\end{array}$ \\
\hline 9 & Female & $<30$ & $\begin{array}{l}\mathrm{RN} \text { with bachelor } \\
\text { degree }\end{array}$ & Home care & $\begin{array}{l}\text { City, southern part of the } \\
\text { Netherlands }\end{array}$ \\
\hline 10 & Female & $<30$ & $\begin{array}{l}\text { RN with associate } \\
\text { level degree }\end{array}$ & Home care & $\begin{array}{l}\text { Rural area, eastern part of } \\
\text { the Netherlands }\end{array}$ \\
\hline II & Female & $30-40$ & $\begin{array}{l}\text { RN with associate } \\
\text { level degree }\end{array}$ & $\begin{array}{l}\text { Residential } \\
\text { elderly care }\end{array}$ & $\begin{array}{l}\text { Rural area, western part } \\
\text { of the Netherlands }\end{array}$ \\
\hline 12 & Female & $<30$ & $\begin{array}{l}\mathrm{RN} \text { with bachelor } \\
\text { degree }\end{array}$ & Home care & $\begin{array}{l}\text { Rural area, eastern part of } \\
\text { the Netherlands }\end{array}$ \\
\hline
\end{tabular}

CNA: Certified Nursing Assistant, RN: Registered Nurse. 
Verkaik, R., Antwerpen-Hogenraad, P. van, Veer, A. de, Francke, A., Huis in het Veld, J. Selfmanagement-support in dementia care: a mixed methods study among nursing staff. Dementia: International Journal of Social Research and Practice: 2017, 16(8), 1032-1044

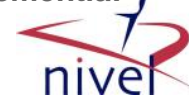

Table 3. Percentage of nursing staff who perform the following self-management support activities.

\begin{tabular}{|c|c|c|c|c|}
\hline $\begin{array}{l}\text { I support self-management } \\
\text { of my clients in the } \\
\text { following activities: }\end{array}$ & Yes & $\begin{array}{l}\text { No, because } \\
\text { it is not my } \\
\text { professional task }\end{array}$ & $\begin{array}{l}\text { No, because it has } \\
\text { never occurred to me, } \\
\text { although it is one of } \\
\text { my professional tasks }\end{array}$ & $\begin{array}{l}\text { No, because clients } \\
\text { do not need these } \\
\text { tasks to be done } \\
\text { for them }\end{array}$ \\
\hline $\begin{array}{l}\text { Deploying activities in personal } \\
\text { care }\end{array}$ & 87.9 & 0.5 & 0.0 & 4.4 \\
\hline $\begin{array}{l}\text { Using tools for self-management } \\
\text { support }\end{array}$ & 85.0 & 1.0 & 0.5 & 6.3 \\
\hline Calling for help if needed (I) & 83.0 & 1.9 & 0.5 & 7.8 \\
\hline $\begin{array}{l}\text { Dealing with limited energy } \\
\text { levels (I) }\end{array}$ & 79.6 & 1.5 & 24 & 9.7 \\
\hline $\begin{array}{l}\text { Learning to deal with emotions } \\
\text { and stress (1) }\end{array}$ & 79.1 & 2.4 & 24 & 8.7 \\
\hline $\begin{array}{l}\text { Understanding the information } \\
\text { from physicians or other } \\
\text { healthcare professionals (I) }\end{array}$ & 78.2 & 3.4 & 1.5 & 9.7 \\
\hline $\begin{array}{l}\text { Encouraging medication } \\
\text { adherence ( } 1)\end{array}$ & 78.2 & 1.5 & 0.5 & 13.1 \\
\hline $\begin{array}{l}\text { Learning to deal with pain or } \\
\text { limitations ( } 1 \text { ) }\end{array}$ & 77.7 & 2.9 & 1.0 & 11.2 \\
\hline $\begin{array}{l}\text { Monitoring the clients' } \\
\text { symptoms (I) }\end{array}$ & 74.8 & 1.5 & 29 & 12.6 \\
\hline $\begin{array}{l}\text { Encouraging the clients' } \\
\text { autonomy (I) }\end{array}$ & 74.8 & 1.9 & 1.9 & 13.6 \\
\hline $\begin{array}{l}\text { Consulting healthcare } \\
\text { professionals when } \\
\text { needed (I) }\end{array}$ & 71.8 & 6.3 & 24 & 11.2 \\
\hline $\begin{array}{l}\text { Letting clients maintain control } \\
\text { of their lives ( } 1 \text { ) }\end{array}$ & 70.9 & 5.8 & 24 & 12.6 \\
\hline $\begin{array}{l}\text { Using family caregivers and } \\
\text { volunteers when needed (I) }\end{array}$ & 67.5 & 8.3 & 3.9 & 12.6 \\
\hline $\begin{array}{l}\text { Visiting physicians or other } \\
\text { healthcare professionals (1) }\end{array}$ & 60.2 & 12.6 & 1.5 & 18.0 \\
\hline $\begin{array}{l}\text { Learning to deal with an } \\
\text { uncertain future ( } 1)\end{array}$ & 60.2 & 6.8 & 5.3 & 19.4 \\
\hline $\begin{array}{l}\text { Letting clients monitor their own } \\
\text { health (I) }\end{array}$ & 56.8 & 7.3 & 4.9 & 23.8 \\
\hline $\begin{array}{l}\text { Encouraging clients to use the } \\
\text { (limited) possibilities to } \\
\text { undertake activities outside } \\
\text { the home (I) }\end{array}$ & 50.5 & 12.1 & 4.9 & 24.3 \\
\hline $\begin{array}{l}\text { Encouraging exercise in the } \\
\text { home (I) }\end{array}$ & 49.5 & 11.7 & 5.3 & 25.7 \\
\hline $\begin{array}{l}\text { Making decisions about } \\
\text { treatment ( } 1 \text { ) }\end{array}$ & 48.1 & 18.4 & 4.9 & 18.9 \\
\hline $\begin{array}{l}\text { Strengthening the client's social } \\
\text { network (I) }\end{array}$ & 46.6 & 18.0 & 7.3 & 20.4 \\
\hline
\end{tabular}

(continued) 
Verkaik, R., Antwerpen-Hogenraad, P. van, Veer, A. de, Francke, A., Huis in het Veld, J. Selfmanagement-support in dementia care: a mixed methods study among nursing staff. Dementia: ) International Journal of Social Research and Practice: 2017, 16(8), 1032-1044

Table 3. Continued.

\begin{tabular}{|c|c|c|c|c|}
\hline $\begin{array}{l}\text { I support self-management } \\
\text { of my clients in the } \\
\text { following activities: }\end{array}$ & Yes & $\begin{array}{l}\text { No, because } \\
\text { it is not my } \\
\text { professional task }\end{array}$ & $\begin{array}{l}\text { No, because it has } \\
\text { never occurred to me, } \\
\text { although it is one of } \\
\text { my professional tasks }\end{array}$ & $\begin{array}{l}\text { No, because clients } \\
\text { do not need these } \\
\text { tasks to be done } \\
\text { for them }\end{array}$ \\
\hline $\begin{array}{l}\text { Making contacts with care and } \\
\text { welfare services (I) }\end{array}$ & 44.2 & 14.6 & 8.7 & 25.7 \\
\hline $\begin{array}{l}\text { Using new technology (for } \\
\text { example: internet or e-health } \\
\text { programmes) to promote self- } \\
\text { management }\end{array}$ & 19.4 & 17.0 & 12.1 & 43.2 \\
\hline
\end{tabular}

(1) a statistically significant difference among healthcare settings $\left(\mathrm{chi}^{2} \mathrm{p}<0.01\right.$ ). 